\title{
Learning and Memory in Transgenic Mice Modeling Alzheimer's Disease
}

\author{
Karen Hsiao Ashe \\ Departments of Neurology and Neuroscience, University of Minnesota, Minneapolis, Minnesota 55455, USA
}

\begin{abstract}
Recent advances in behavioral analyses of transgenic mouse models of Alzheimer's disease (AD) are discussed, and their impact on our understanding of the molecular basis of cognitive impairment in AD is considered. Studies of the relationship between memory and Aß in transgenic mice expressing the amyloid precursor protein (APP) and its variants suggest that aging promotes the formation of soluble Aß assemblies mediating negative effects on memory. A significant component of memory loss in APP transgenic mice is apparently caused by soluble Aß assemblies, but whether and how much of the dementia within individuals afflicted with $A D$ is caused by these $A ß$ species is unclear. Future studies in composite transgenic mice developing amyloid plaques, neurofibrillary tangles, and other $\mathrm{AD}$ pathology may allow for the determination of the relative contribution of $A ß$ and non-Aß components to dementia.
\end{abstract}

The current optimism that meaningful treatments for Alzheimer's disease (AD) are imminent has been generated using transgenic mice modeling $\mathrm{AD}$ as test subjects (Schenk et al. 1999; Bard et al. 2000; Janus et al. 2000; Lim et al. 2000; Morgan et al. 2000; Cherny et al. 2001; Dovey et al. 2001). Transgenic mice modeling $\mathrm{AD}$ have been reported by over 20 research groups. These mice were created by expressing variants of amyloid precursor protein (APP), presenilin-1 (PS1) or presenilin-2, tau or apolipoprotein E. As a family the mice develop a wide variety of behavioral, biochemical, pathological, and physiological traits simulating $\mathrm{AD}$, although not all traits have been represented within an individual mouse line. All of the transgenic mice used to evaluate potential therapeutic interventions have been APP transgenic mice or APP/PS1 bigenic mice, because they are the only transgenic mouse models of $\mathrm{AD}$ in which both amyloid deposition and progressive memory loss have been shown. The lack of neurofibrillary tangles or significant neuronal loss in APP or APP/PS1 mice makes it necessary to temper predictions of how interventions benefiting mice with only some of the pathological hallmarks of $\mathrm{AD}$ will affect humans afflicted with the actual disorder. Although it is possible to produce both amyloid plaques and neurofibrillary tangles within individual mice by crossing APP to tau transgenic mice, the resultant mice are not suitable for learning or memory assessments because they become paralyzed (Lewis et al. 2001). Testing of compounds and interventions in mice with more comprehensive phenotypes awaits further refinement of transgenic models of $\mathrm{AD}$, but carefully interpreted treatment studies using currently available mice are nonetheless valuable.

The main objectives of this review are to discuss recent advances in behavioral analyses of transgenic mouse models

E-MAIL hsiao005@umn.edu; FAX (612) 626-2639.

Article and publication are at http://www.learnmem.org/cgi/doi/ $10.1101 / \mathrm{lm} .43701$. of $\mathrm{AD}$ and to consider their impact on our understanding of the molecular basis of cognitive impairment in AD. For thoughtful summaries of genetic parameters, neuropathology, and behavioral studies in APP transgenic mice, see reviews by Westaway and colleagues (Janus et al. 2000) and by Chapman et al. (2001). A comprehensive, annotated transgenic mouse directory is accessible at http://staging.alzforum.org/members/resources/Transgenic/index.html (Alzheimer Research Forum 2001).

\section{Dementia and Memory Loss}

\section{Mechanisms of Dementia in $A D$}

Memory loss is the cardinal and one of the earliest clinical manifestations of AD. Therefore, the efficacy of any given intervention will ultimately be judged upon its ability to prevent memory loss or restore memory ability. New therapeutic measures against dementia in $\mathrm{AD}$ are being aimed at a variety of targets deemed instrumental in the pathogenesis of the disease. The two main targets are amyloid plaques and neurofibrillary tangles and their principal molecular components, $A ß$ and tau.

The $\mathrm{A} ß$ hypothesis of $\mathrm{AD}$ stipulates that $\mathrm{A} \beta$ aggregates to form amyloid plaques that are neurotoxic, leading to neurodegeneration accompanied by dementia. The strongest evidence for this hypothesis comes from molecular genetic studies of APP and presenilins in familial AD showing that all mutations increased the propensity for $A ß$ to aggregate in vitro. Studies of the modifier gene product, apolipoprotein E, showing enhanced susceptibility conferred by the $\mathrm{E} 4$ allele also found that the $\mathrm{E} 4$ isoform increased the rate of $A ß$ aggregation.

The principal argument against $A ß$ stems from multiple studies showing little or no correlation between the number or size of amyloid deposits and dementia. In some reports synaptic loss and neurofibrillary tangles appear to correlate better with various measures of memory loss (Terry et al. 1991; Arriagada et al. 1992; Berg et al. 1993). Although

LEARNING \& MEMORY 8:301-308 @ 2001 by Cold Spring Harbor Laboratory Press ISSN1072-0502/01 \$5.00




no cases of $\mathrm{AD}$ are linked to mutations in tau, some familial dementias characterized by neurofibrillary tangles without amyloid deposits are linked to tau mutants (Hutton et al. 1998; Poorkaj et al. 1998; Spillantini et al. 1998). This indicates that abnormal tau metabolism can also lead to dementia.

\section{Measuring Memory in APP Transgenic Mice}

One of the main challenges in cognitive studies of APP transgenic mice has been determining the onset of memory deficits. This is an important challenge because identifying molecules causing memory loss depends upon accurately determining when cognitive deficits first appear. Two factors have made this a potentially difficult determination to address. The first concerns the subtlety of initial memory deficits and whether the behavioral tests used are sufficiently sensitive to detect small, early changes. The second concerns the presence of age-independent behavioral deficits that might not be well distinguished from age-dependent learning and memory deficits and whether testing procedures and analyses distinguish between these processes.

Another significant problem in assessing memory in APP transgenic mice has been measuring memory ability across the entire life span of the mouse. This is critical for correlating memory loss with molecular markers appearing at different stages of disease. The main difficulty in this task is that the dynamic range for changes in molecular markers of $\mathrm{AD}$ is very large, whereas the dynamic range (i.e., the parametric space represented between the "ceiling" and "floor") for many popular behavioral procedures may be quite small. Unless all stages of cognitive failure are measurable within the dynamic range of a given behavioral procedure, meaningful data relating cognitive changes to molecular markers at different stages of disease cannot be generated.

Similar issues have been raised testing AD patients. Delayed recall for stories and figures discriminate mild cases from normal subjects well but show rapid deterioration to an early floor and are therefore poor for staging (Locascio et al. 1995). On the other hand, confrontation naming, semantic fluency, and immediate recognition of geometric figures show steady linear decline across time for patients with AD and are better tests for staging dementia severity (Locascio et al. 1995). Most studies comparing clinical status with brain pathology at autopsy use the MMSE (Mini-mental status exam; Folstein et al. 1975), the Blessed IMC (information, memory, and concentration) test (Blessed et al. 1968), or the CDR (Clinical dementia rating; Morris 1993), each of which provides a different composite measure of various aspects of global cognitive function. They correlate well with each other and exhibit a broad dynamic range covering all stages of $\mathrm{AD}$ (Cummings et al. 1996). However, the broad dynamic range is achieved at the expense of reduced selectivity for particular aspects of cognitive function.

Age-related behavioral deficits have been reported in five lines of APP transgenic mice (Table 1). Moran et al. were the first to measure spatial reference memory in an APP transgenic mouse line. Using the Morris water maze, they studied NSE:ß-APP751, a line that was homozygous for a transgene array expressing wild-type human APP751, and showed an age-dependent deterioration in the ability of mice to generate a search bias (Moran et al. 1995). Mice at 5-6 mo of age showed a search bias, but by 9-12 mo, they swam in a random pattern in all three probe trials performed at equal intervals during the 9-d training. During the probe trials, the swim pattern of the mouse was recorded after the submerged platform was removed, and the relative amount of time spent in the vicinity of the location of the platform is an indication of spatial memory. Interestingly, the escape latencies in both the hidden and visible versions of the test were slow in both age groups, possibly indicative of an age-independent deficit.

Morris and colleagues measured spatial working memory in PDAPP mice using a water maze protocol in which the location of the platform was changed between five successive groups of training trials (Chen et al. 2000). Transgene-positive mice performed less well than transgene-negative mice at the earliest tested age of 6-9 mo, and the difference between transgene-positive and -negative mice increased significantly with age. Further analysis revealed an age-independent component of impairment in the transgene-positive mice that was discerned during training to the first platform. This was distinct from an age-dependent component detected during training to the last two platforms and which was normal at 6-9 mo but abnormal at 13-15 mo and older. Whether these two components were related to the effects of Aß or overexpression of APP was not specifically addressed because transgenic mice expressing an equivalent amount of wild-type APP were not available for comparison. However, a weak, but statistically significant inverse correlation $\left(r^{2}=0.25\right)$ was found between amyloid load and learning capacity, defined as the number of different platform positions a mouse could learn before failing to learn more, suggesting a relationship between performance in this task and plaque deposition.

TgCRND8 mice showed impaired spatial reference learning and memory in the conventional Morris water maze at the earliest tested age of 3 mo (Janus et al. 2000; Chishti et al., 2001). Because of retest effects, no clear progression of the deficit was shown. Because no mice expressing comparable levels of wild-type APP were tested in parallel, the possibility that this early deficit was due to APP overexpression per se cannot be excluded. However, significantly better spatial acquisition observed in 11-wk mice immunized for 5 wk against Aß42, as opposed to control peptide (islet-associated polypeptide), implicated Aß. A progression of the deficit between 6 and $11 \mathrm{wk}$ of age could be inferred by the finding that spatial learning and memory in 11-wk mice immunized against Aß42 was similar to that of nontransgenic mice.

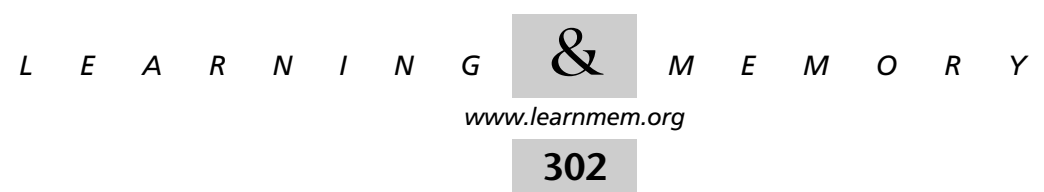




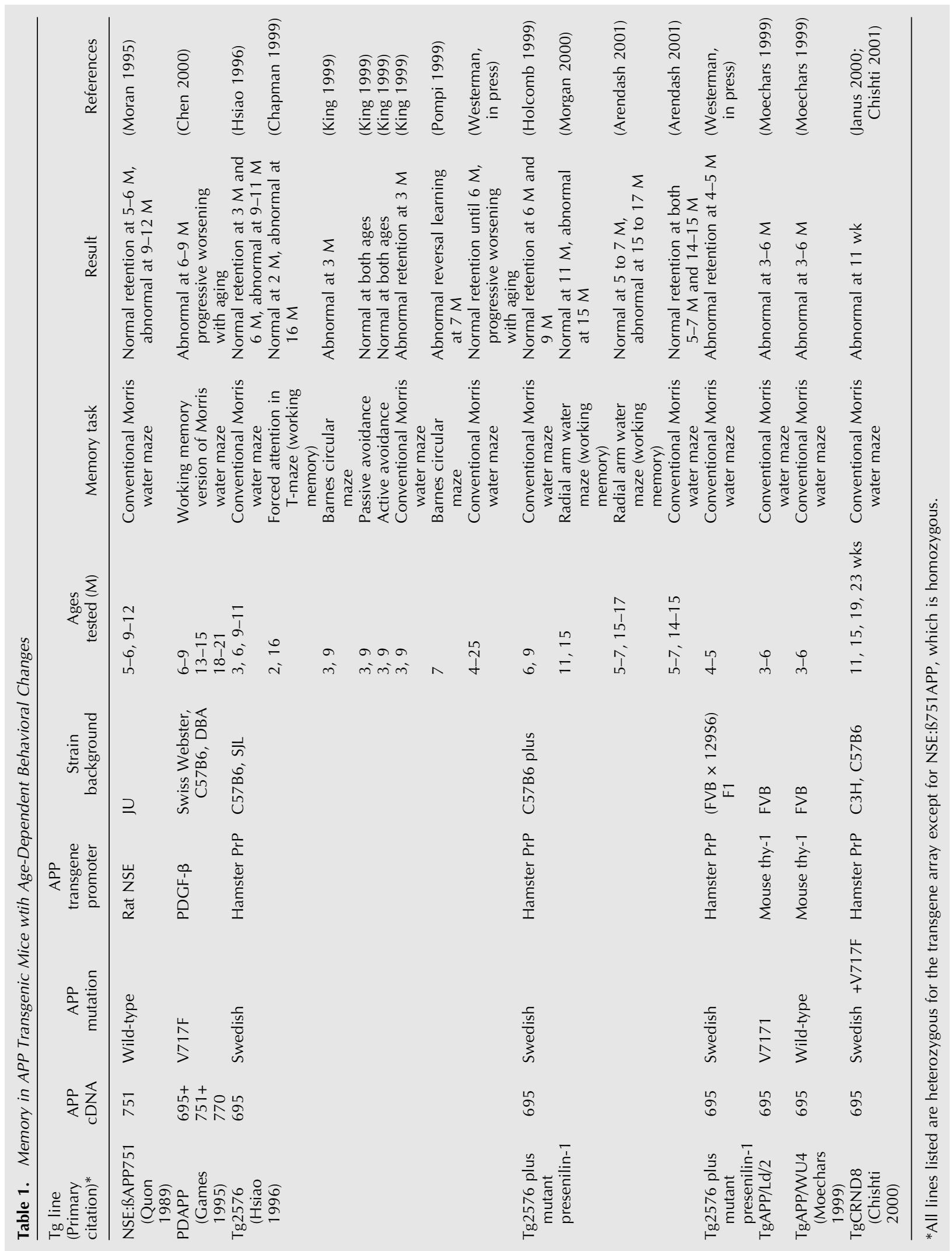

$$
\text { n...... }
$$


When mutant or wild-type APP was expressed in transgenic mice in an FVB strain background, a wide variety of physical and behavioral abnormalities occurred, including premature death, neophobia, aggression, and seizures (Hsiao et al. 1995; Moechars et al. 1996, 1999). These abnormalities have not been observed in the other commonly used backgrounds, C57B6, 129S6, C3H, DBA, and Swiss Webster or mixtures thereof. The rates at which they occur in the FVB strain background depend upon APP expression levels. Van Leuven and colleagues reported that 3- to 6-month-old mice in a B6FVBF1 background expressing either APP with the V717I mutation or wild-type APP exhibit impaired spatial reference learning and memory in the conventional Morris water maze (Moechars et al. 1999). They did not determine the age at which this impairment became apparent or whether it progressed with aging, however (Moechars et al. 1999). It has been difficult to ascribe the various physical and behavioral abnormalities or the memory impairment in these mice to APP or to cleavage products of APP, including APP $\alpha$, APP $\beta$, C-terminal fragments, or Aß (Moechars et al. 1999). The propensity for these mice to seize may complicate the interpretation of cognitive studies, making this problem potentially more difficult to solve in FVB mice.

Memory in $\operatorname{Tg} 2576$ mice has been measured by several groups. Various reports about the onset of cognitive deficits in Tg2576 have indicated abnormalities appearing as early as $3 \mathrm{mo}$, as late as $15 \mathrm{mo}$, and at intermediate ages (Hsiao et al. 1996; Chapman et al. 1999; King et al. 1999; Pompl et al. 1999; Morgan et al. 2000; Westerman et al., in press). The discrepancies between these studies are probably related to differences in the sensitivities and dynamic ranges of the various behavioral procedures used to test memory and to differences in the ability to distinguish age-independent behavioral abnormalities from age-dependent memory deficits (Westerman et al., in press). Ashe and colleagues found age-independent performance deficits related to both mutant and wild-type human APP overexpression by studying transgenic mice overexpressing wild-type human $\mathrm{APP}_{695}$ at a level equivalent to mutant $\mathrm{APP}_{695}$ in $\mathrm{Tg} 2576$ (Westerman et al., in press). When mice with these deficits that were not specifically related to the expression of mutant $\mathrm{APP}_{695}$ were excluded from the analysis and when probe trials were interpolated early during training to increase the sensitivity of the Morris water maze test, spatial memory loss was first detected at $\sim 6 \mathrm{mo}$. These results are supported by studies of Tg2576 mice trained longitudinally to respond to a fixed consecutive number "five" operant paradigm (Cleary et al. 2000) or to alternate in a T-maze (P. Chapman, unpubl.), both showing overlapping performance of transgene-positive and -negative mice until $\sim 7-8$ mo.

These findings differ from two studies that failed to detect spatial acquisition or retention deficits in 9-monthold Tg2576 mice using the Morris water maze (Holcomb et al. 1999; King et al. 1999), well after the appearance of detergent-insoluble $\mathrm{A} \beta$, and a third showing no significant deficit in spatial retention in mice bigenic for the $\mathrm{Tg} 2576$ transgene array and mutant presenilin-1 at 15-17 mo (Arendash et al. 2001). In all three studies, probe trials were performed only after extensive training that probably saturated learning and reduced the sensitivity of the test.

Chapman et al. (1999) showed a correlation between working memory in the T-maze and long-term-potentiation (LTP) recorded in vitro in the CA1 and dentate gyrus of the hippocampus of Tg2576 mice. Reductions in LTP recorded in vitro were present in old (16- to 17-month-old) but not young (2- to 8-month-old) mice. However, when hippocampal slices from behaviorally naïve old mice were incubated for several hours in NMDA antagonists prior to recording, LTP in old mice was normal (Fitzjohn et al. 2001; P. Chapman, unpubl.). Taken together, these results suggest increased vulnerability of $\mathrm{Tg} 2576$ hippocampal slices to NMDA-mediated excitotoxic damage with age and that in vitro LTP in some circumstances may reflect the susceptibility of Tg2576 hippocampal tissue to the trauma of slice preparation, rather than long-lasting synaptic plasticity. The vulnerability of the tissue appears to increase with worsening cognitive function, accounting for the correlation between working memory and LTP. However, this would not explain the diminution of LTP recorded in vivo in the dentate gyrus of 13- to 15-month-old Tg2576 mice (Chapman et al. 1999). There are several possible reasons for the disparity between in vitro and in vivo LTP results in Tg2576, including the presence of a diffusible factor disrupting cognition that might be diluted in slice preparations, the involvement of modulating afferent pathways to the hippocampus that would be severed in slice preparations, or the contributions of synaptically mediated cerebrovascular responses that would make no contributions in vitro. Of note, in vivo LTP in the dentate gyrus of rats is also diminished following local infusions of Aß43 and Aß40 combined but not of the same doses of peptides separately (Stephan et al. 2001). Because the combination of peptides is more likely to aggregate than either peptide alone, these results support the idea that the formation of aggregated $A ß$ impairs synaptic plasticity.

\section{Molecular Correlates of Memory Loss in APP Transgenic Mice}

Multiple studies in APP transgenic mice have supported the idea that memory loss and Aß are related (Hsiao et al. 1995, 1996; Chen et al. 2000; Janus et al. 2000; Morgan et al. 2000; Gordon et al. 2001; Westerman et al., in press). However, there is no consensus about which form of $A ß$ may be responsible. Various forms of $\mathrm{A} \Omega$, characterized by their aggregation states, are to be found in the brains of APP transgenic mice at different ages (Kawarabayashi et al. 2001). Antibody-based detection methods are the most




popular means by which these different forms of $A ß$ are measured, either in situ using immunohistopathological techniques or in detergent-extracted brain tissue assayed by enzyme-linked immunosorbent assay (Kawarabayashi et al. 2001). Although the detergent extractions are enriched for specific $A ß$ species, each fraction potentially contains a mixture of several $A ß$ species.

The first report studying the relationship between memory and $A ß$ showed the onset of spatial reference memory loss (using the Morris water maze) at 9 mo was associated with rising levels of total $A ß$ and the appearance of amyloid deposits in Tg2576 mice (Hsiao et al. 1996). Using a more sensitive and specific water maze protocol, the onset of deficits in Tg2576 mice was subsequently assigned to $\sim 6 \mathrm{mo}$, coinciding with the appearance of detergent-insoluble $A ß$ aggregates but prior to mature plaque deposition (Westerman et al., in press). TgCRND8 mice show a rapid rise in $A ß$ at $10 \mathrm{wk}$, probably indicative of the appearance of detergent-insoluble Aß aggregates (Chishti et al. 2001), and show Aß-dependent spatial memory deficits at 11 wk (Janus et al. 2000; Chishti et al. 2001). These findings are consistent with the observation in $\mathrm{Tg} 2576$ mice that the earliest changes in memory are associated with the appearance of detergent-insoluble Aß. Genetically accelerating the formation of detergent-insoluble $A ß$ aggregates resulted in an earlier onset of memory loss in Tg2576 mice (Westerman et al., in press), further corroborating this association. Two correlative studies in PDAPP mice and mice bigenic for the mutant presenilin-1 and Tg2576 transgenes showed significant negative correlations between memory and amyloid load (Chen et al. 2000; Gordon et al. 2001). One interpretation of these observations is that memory loss in APP transgenic mice is closely associated with detergent-insoluble $A ß$ aggregates, some of which may be below the threshold of histopathological detection. However, results of investigations of APP transgenic mice across a broader age range argued against such a simple relationship between memory and detergent-insoluble Aß (Westerman et al., in press). This is discussed more thoroughly below.

Two procedures measuring spatial working memory appear to lack the necessary sensitivity to detect changes coinciding with the appearance of detergent-insoluble Aß. Using a working-memory version of the Morris water maze, deterioration in the age-dependent component of working memory in PDAPP mice was first detected at 13-15 mo and not at 6-9 mo (Chen et al. 2000), although a rapid rise in Aß occurred much earlier between 4 and 8 mo (Johnson-Wood et al. 1997). Nor is working memory in Tg2576 mice measured in the radial arm water maze able to detect abnormalities at $\sim 6 \mathrm{mo}$, the age at which the conversion of detergent-soluble to insoluble Aß first occurs. The earliest reported deficits in radial arm water maze performance were in 15-month-old Tg2576 mice and no deficits were found at 11 mo (Morgan et al. 2000). It is possible that spatial work- ing memory is preserved longer than spatial reference memory and is unrelated to the conversion of detergentsoluble to insoluble Aß in Tg2576 and PDAPP mice. However, mitigating against this possibility is the finding that acquisition of forced alternation in a T-maze task, another test of spatial working memory, detects deficits in Tg2576 mice as early as $\sim 7-8$ mo (P. Chapman, unpubl.). It is more likely that the dynamic ranges of the currently used paradigms to measure spatial working memory in the water maze are tuned to reveal more severe age-dependent deficits occurring in older Tg2576 and PDAPP mice but may miss the more subtle abnormalities developing in younger mice.

The hypothesis that memory loss and detergent-insoluble $A ß$ are closely connected breaks down when mice at multiple ages spanning a broad age range are examined. This break down would not have been evident in previous studies examining only one age range (Chen et al. 2000; Gordon et al. 2001). In Tg2576 mice no obvious correspondence between memory and detergent-insoluble Aß was apparent in a combined group of old (21-22 mo) and young (5-6 mo) mice unless the mice were stratified by age, whereupon inverse correlations between memory and detergent-insoluble Aß became evident (Westerman et al., in press). These results suggested that detergent-insoluble $A ß$ is a surrogate marker for small assemblies of $A ß$ that disrupt cognition and occur as intermediates during amyloid plaque formation (Fig. 1). Importantly, detergent-insoluble $A ß$ in some cognitively intact old $\mathrm{Tg} 2576$ mice was a hundred to a thousand times higher than in impaired young Tg2576 mice (Westerman et al., in press). Ashe and colleagues concluded that these $A ß$ assemblies reside in the soluble $A ß$ fraction because it would be difficult to explain how some old mice with very high levels of detergent-insoluble $A ß$ could have relatively normal cognitive function otherwise. The idea that soluble Aß species might be responsible for memory deficits in APP transgenic mice was proposed initially to explain how memory loss was more successfully prevented in $A ß$ vaccination studies than plaque deposition (Morgan et al. 2000) or Aß accumulation (Janus et al. 2000) and why PDAPP mice lacking APOE showed dramatically reduced plaque deposition but appeared to have slightly worse memory (Dodart et al. 2000). Taken along with the studies by Ashe and colleagues (Westerman et al., in press), these results challenge the classic amyloid cascade model but are in keeping with in vitro studies showing neurotoxic properties of small Aß assemblies (Roher et al. 1996; Lambert et al. 1998; Hartley et al. 1999; Hsia et al. 1999; Wang et al. 1999; Mucke et al. 2000).

\section{Relevance to Alzheimer's Disease}

This idea might also explain a puzzling inconsistency in the relationship between amyloid load and memory in AD. Several early reports showed little or no correlation between amyloid load and dementia (Terry et al. 1991; Arriagada et

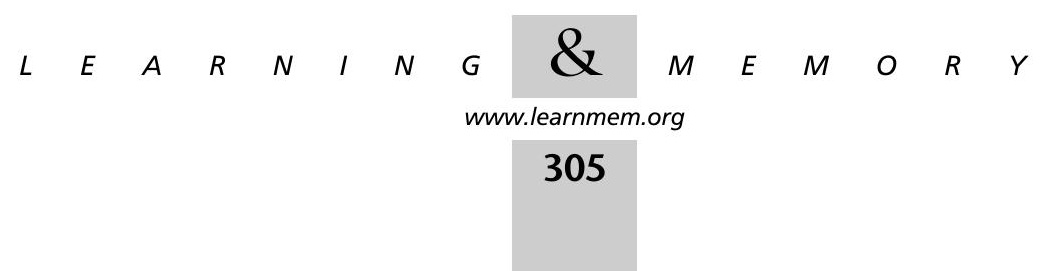




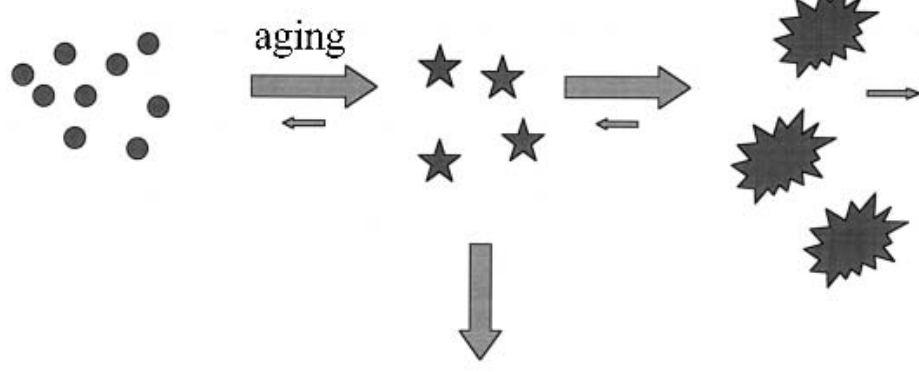

memory loss

Figure 1 Model summarizing relationship between memory and $A B$ in amyloid precursor protein transgenic mice. The hypothetical cascade involves the conversion of monomeric $A ß$ (circles) to small $A ß$ assemblies (stars), which in turn disrupt cognitive function. This contrasts with the classic amyloid cascade hypothesis, in which dementia is believed to result from neuronal destruction associated with amyloid plaques (starbursts). Amyloid load may be a surrogate marker for the cognitively disruptive small $A B$ assemblies. If so, then it follows that three independent factors influencing amyloid load, namely the duration of disease, the conversion rates between soluble and insoluble $A \beta$, and the degradation rate of insoluble $A B$, must be taken into account when selecting subject pools. Doing otherwise could obscure the relationship between amyloid deposition and dementia.

al. 1992; Berg et al. 1993). More recently, when more sensitive antibody-based methods were used to measure Aß deposits and subject pools that represented a broad range of cognitive impairment were examined, highly significant and robust correlations were found (Cummings et al. 1996; Bartoo et al. 1997; Naslund et al. 2000). In spite of these methodological improvements, however, it has remained difficult to explain why some individuals with high plaque loads are cognitively normal (Katzman et al. 1988; Delaere et al. 1990; Dickson et al. 1992). Some possibilities are that these individuals have greater cognitive reserve or are less susceptible to amyloid plaques. The results of investigations in Tg2576 mice suggested another possibility (Westerman et al., in press). If cognitive decline is due to small $A ß$ assemblies formed during the conversion of detergent-soluble to -insoluble $A ß$, then certain individuals with low levels of these $A ß$ assemblies could be cognitively intact but would nevertheless accumulate large amounts of deposits or $A \beta_{\text {insol }}$ over time. The studies in APP transgenic mice also illustrate how correlations between $A ß$ and memory can be either instructive or potentially misleading (Fig. 2).

In conclusion, recent studies of the relationship between memory and Aß in APP transgenic mice suggest that aging promotes the formation of soluble $A ß$ assemblies mediating negative effects on memory. The conditions in the brain promoting assembly of monomeric Aß into oligomeric species are unknown. Although these $A ß$ assemblies disrupting memory have not yet been isolated from brain tissue, they may be related to one or

$\begin{array}{ccc}\circ & \bullet & \bullet \\ \text { younger } & \text { in-berween } & \text { older }\end{array}$

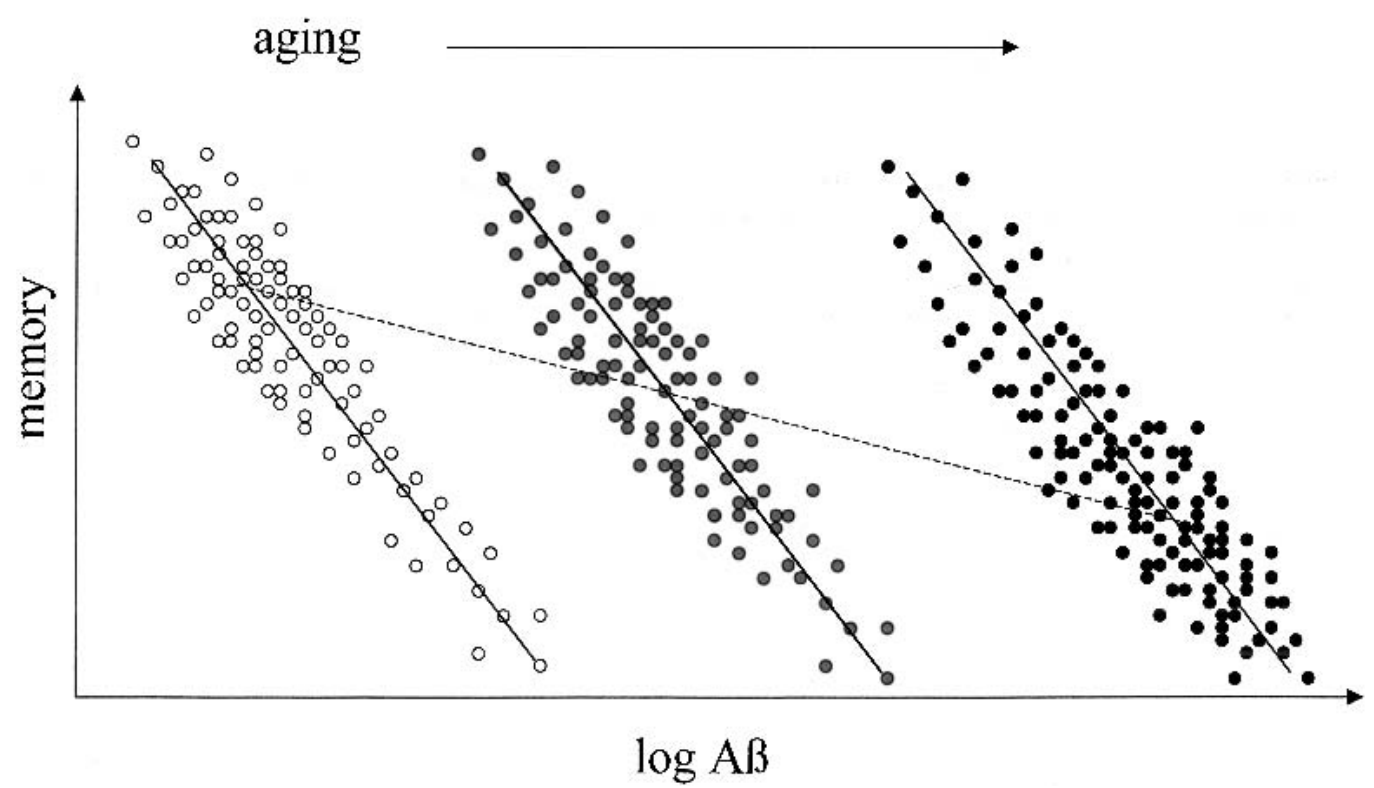

Figure 2 Hypothetical schematic showing the relationship between memory and Aß stratified by age. There is a negative correlation between memory and $A B$ in mice within each age group (solid regression line). When very large numbers of mice are examined across a broad range of ages, a less robust inverse relationship between memory and $A ß$ may emerge (dashed line). The basis of the latter relationship lies in the gradual shift of the distribution of memory scores in aging mice from higher to lower values.

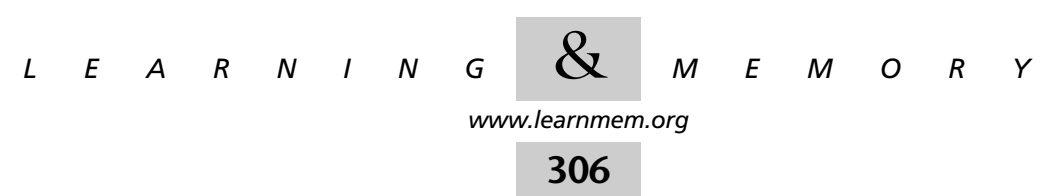


more Aß species that recently have been synthesized and studied in vitro. A significant component of memory loss in APP transgenic mice is apparently caused by soluble Aß assemblies, but whether and how much of the dementia within individuals with $\mathrm{AD}$ is caused by these $\mathrm{A} ß$ species is not clear. Whether progressive worsening of cognition in $\mathrm{Tg} 2576$ and $\mathrm{AD}$ is due to accumulation of cognitively disruptive $\mathrm{A} ß$ intermediates or to superimposed toxic effects associated with fibrillar Aß and plaque-related neuropathology is unknown.

\section{Conclusion}

Since the creation of the first transgenic mice modeling AD twelve years ago, studies of these and subsequently generated mice have provided important information about salient histopathological features of AD. However, until recently the pathogenesis of memory loss in these mice was poorly understood. The major impediment to elucidating the relationship between cognitive function and molecular markers has been the difficulty of distinguishing between age-dependent and age-independent changes in behavior and cognition in APP transgenic mice. The development and analysis in parallel of APP transgenic mice expressing levels of wild-type APP comparable to mutant APP aided in segregating behavioral effects that were not specifically related to mutant APP expression. Refinement of behavioral tests provided the necessary sensitivity and dynamic range to obtain measures of memory ability that mapped well onto post-translational modifications of the leading molecular candidate, Aß. These descriptive characterizations alongwith active Aß immunization studies in APP transgenic micehave shown that $A ß$ is necessary and sufficient to disrupt memory and implicate a cognitively disruptive soluble $A ß$ species.

The hypothesis that small Aß assemblies formed during the conversion of soluble to insoluble $A ß$ cause memory loss helps reconcile conflicting results obtained in investigations of the relationship between amyloid load and dementia in patients with $\mathrm{AD}$. By reconciling the studies showing poor correlations between amyloid load and cognitive status with the Aß hypothesis, the major argument against the role of $\mathrm{A} \Omega$ in the pathogenesis of $\mathrm{AD}$ is weakened. However, it is unlikely that non-Aß components in the $\mathrm{AD}$ brain exert no effect whatsoever on brain function. Future studies in composite transgenic mice developing amyloid plaques, neurofibrillary tangles, and other AD pathology may allow for the determination of their relative contributions to dementia.

\section{ACKNOWLEDGMENTS}

I thank Marcus Westerman for his insightful intellectual and scientific contributions and Paul Chapman for his helpful critique of this manuscript. Supported by the NIH (AG15453 and NS33249).

\section{REFERENCES}

Arendash, G.W., King, D.L., Gordon, M.N., Morgan, D., Hatcher, J.M.,
Hope, C.E., and Diamond, D.M. 2001. Progressive, age-related behavioral impairments in transgenic mice carrying both mutant amyloid precursor protein and presenilin-1 transgenes. Brain Res. 891: $42-53$.

Arriagada, P.V., Growdon, J.H., Hedley-Whyte, E.T., and Hyman, B.T. 1992. Neurofibrillary tangles but not senile plaques parallel duration and severity of Alzheimer's disease. Neurology 42: 631-639.

Bard, F., Cannon, C., Barbour, R., Burke, R.L., Games, D., Grajeda, H., Guido, T., Hu, K., Huang, J., Johnson-Wood, K., et al. 2000. Peripherally administered antibodies against amyloid $\beta$-peptide enter the central nervous system and reduce pathology in a mouse model of Alzheimer disease. Nat. Med. 6: 916-919.

Bartoo, G.T., Nochlin, D., Chang, D., Kim, Y., and Sumi, S.M. 1997. The mean $A \beta$ load in the hippocampus correlates with duration and severity of dementia in subgroups of Alzheimer disease. $J$. Neuropathol. Exp. Neurol. 56: 531-540.

Berg, L., McKeel Jr., D.W., Miller, J.P., Baty, J., and Morris, J.C. 1993. Neuropathological indexes of Alzheimer's disease in demented and nondemented persons aged 80 years and older. Arch. Neurol. 50: 349-358.

Blessed, G., Tomlinson, B.E., and Roth, M. 1968. The association between quantitative measures of dementia and of senile change in the cerebral grey matter of elderly subjects. Br. J. Psychiatry $114: 797-811$.

Chapman, P.F., White, G.L., Jones, M.W., Cooper-Blacketer, D., Marshall, V.J., Irizarry, M., Younkin, L., Good, M.A., Bliss, T.V., Hyman, B.T., et al. 1999. Impaired synaptic plasticity and learning in aged amyloid precursor protein transgenic mice. Nat. Neurosci. 2: 271-276.

Chapman, P.F., Falinska, A.M., Knevett, S.G., and Ramsay, M.F. 2001. Genes, models and Alzheimer's disease. Trends Genet. 17: 254-261.

Chen, G., Chen, K.S., Knox, J., Inglis, J., Bernard, A., Martin, S.J., Justice, A., McConlogue, L., Games, D., Freedman, S.B., et al. 2000. A learning deficit related to age and $\beta$-amyloid plaques in a mouse model of Alzheimer's disease. Nature 408: 975-979.

Cherny, R.A., Atwood, C.S., Xilinas, M.E., Gray, D.N., Jones, W.D., McLean, C.A., Barnham, K.J., Volitakis, I., Fraser, F.W., Kim, Y., et al. 2001. Treatment with a copper-zinc chelator markedly and rapidly inhibits $\beta$-amyloid accumulation in Alzheimer's disease transgenic mice. Neuron 30: 665-676.

Chishti, M.A., Yang, D.S., Janus, C., Phinney, A.L., Horne, P., Pearson, J., Strome, R., Zucker, N., Loukides, J., French, J., et al. 2001. Early-onset amyloid deposition and cognitive deficits in transgenic mice expressing a double mutant form of APP695. J. Biol. Chem. 15:15.

Cleary, J.P., Ghilardi, J.R., Maggio, J.E., Mantyh, P.W., Hofmeister, J.J., Fritz, M., Ashe, K.H., and O'Hare, E. 2000. Immunization against Aß in APP-overexpressing transgenic mice. Soc. Neurosci. Abs. 26: 497.

Cummings, B.J., Pike, C.J., Shankle, R., and Cotman, C.W. 1996. $\beta$-amyloid deposition and other measures of neuropathology predict cognitive status in Alzheimer's disease. Neurobiol. Aging 17: 921-933.

Delaere, P., Duyckaerts, C., Masters, C., Beyreuther, K., Piette, F., and Hauw, J.J. 1990. Large amounts of neocortical $\beta$ A4 deposits without neuritic plaques nor tangles in a psychometrically assessed, non-demented person. Neurosci. Lett. 116: 87-93.

Dickson, D.W., Crystal, H.A., Mattiace, L.A., Masur, D.M., Blau, A.D., Davies, P., Yen, S.H., and Aronson, M.K. 1992. Identification of normal and pathological aging in prospectively studied nondemented elderly humans. Neurobiol. Aging 13: 179-189.

Dodart, J.C., Mathis, C., Bales, K.R., Paul, S.M., and Ungerer, A. 2000. Behavioral deficits in APP $(V 717 \mathrm{~F})$ transgenic mice deficient for the apolipoprotein E gene. Neuroreport 11: 603-607.

Dovey, H.F., John, V., Anderson, J.P., Chen, L.Z., de Saint Andrieu, P., Fang, L.Y., Freedman, S.B., Folmer, B., Goldbach, E., Holsztynska, E.J., et al. 2001. Functional $\gamma$-secretase inhibitors reduce $\beta$-amyloid peptide levels in brain. J. Neurocbem. 76: 173-181.

Fitzjohn, S.M., Morton, R.A., Kuenzi, F., Rosahl, T.W., Shearman, M., Lewis, H., Smith, D., Reynolds, D.S., Davies, C.H., Collingridge, G.L., et al. 2001. Age-related impairment of synaptic transmission but normal long-term potentiation in transgenic mice that overexpress the human APP695SWE mutant form of amyloid precursor protein. J. Neurosci. 21: 4691-4698. 
Folstein, M.F., Folstein, S.E., and McHugh, P.R. 1975. 'Mini-mental state'. A practical method for grading the cognitive state of patients for the clinician. J. Psychiatr. Res. 12: 189-198.

Games, D., Adams, D., Alessandrini, R., Barbour, R., Berthelotte, P., Blackwell, C., Carr, T., Clemens, J., Donaldson, T., Gillespie, F., et al. 1995. Alzheimer-type neuropathology in transgenic mice overexpressing V717F $\beta$-amyloid precursor protein. Nature 373: 523-527.

Gordon, M.N., King, D.L., Diamond, D.M., Jantzen, P.T., Boyett, K.V., Hope, C.E., Hatcher, J.M., DiCarlo, G., Gottschall, W.P., Morgan, D., et al. 2001. Correlation between cognitive deficits and $A \beta$ deposits in transgenic APP+PS1 mice. Neurobiol. Aging 22: 377-385.

Hartley, D.M., Walsh, D.M., Ye, C.P., Diehl, T., Vasquez, S., Vassilev, P.M., Teplow, D.B., and Selkoe, D.J. 1999. Protofibrillar intermediates of amyloid $\beta$-protein induce acute electrophysiological changes and progressive neurotoxicity in cortical neurons. J. Neurosci. 19: 8876-8884.

Holcomb, L.A., Gordon, M.N., Jantzen, P., Hsiao, K., Duff, K., and Morgan, D. 1999. Behavioral changes in transgenic mice expressing both amyloid precursor protein and presenilin-1 mutations: Lack of association with amyloid deposits. Behav. Genet. 29: 177-185.

Hsia, A.Y., Masliah, E., McConlogue, L., Yu, G.Q., Tatsuno, G., Hu, K., Kholodenko, D., Malenka, R.C., Nicoll, R.A., and Mucke, L. 1999. Plaque-independent disruption of neural circuits in Alzheimer's disease mouse models. Proc. Natl. Acad. Sci. 96: 3228-3233.

Hsiao, K.K., Borchelt, D.R., Olson, K., Johannsdottir, R., Kitt, C., Yunis, W., Xu, S., Eckman, C., Younkin, S., Price, D., et al. 1995. Age-related CNS disorder and early death in transgenic FVB/N mice overexpressing Alzheimer amyloid precursor proteins. Neuron 15: $1203-1218$.

Hsiao, K., Chapman, P., Nilsen, S., Eckman, C., Harigaya, Y., Younkin, S., Yang, F., and Cole, G. 1996. Correlative memory deficits, Aß elevation, and amyloid plaques in transgenic mice. Science 274: 99-102.

Hutton M, Lendon CL, Rizzu P, Baker M, Froelich S, Houlden H, Pickering-Brown S, Chakraverty S, Isaacs A, Grover A, et al. 1998. Association of missense and $5^{\prime}$-splice-site mutations in tau with the inherited dementia FTDP-17. Nature 393: 702-705.

Janus, C., Pearson, J., McLaurin, J., Mathews, P.M., Jiang, Y., Schmidt, S.D., Chishti, M.A., Horne, P., Heslin, D., French, J., et al. 2000. A $\beta$ peptide immunization reduces behavioural impairment and plaques in a model of Alzheimer's disease. Nature 408: 979-982.

Johnson-Wood, K., Lee, M., Motter, R., Hu, K., Gordon, G., Barbour, R., Khan, K., Gordon, M., Tan, H., Games, D., et al. 1997. Amyloid precursor protein processing and $\mathrm{A} \beta 42$ deposition in a transgenic mouse model of Alzheimer disease. Proc. Natl. Acad. Sci. 94: $1550-1555$.

Katzman, R., Terry, R., DeTeresa, R., Brown, T., Davies, P., Fuld, P., Renbing, S., and Peck, A. 1988. Clinical, pathological, and neurochemical changes in dementia: A subgroup with preserved mental status and numerous neocortical plaques. Ann. Neurol. 23: $138-144$

Kawarabayashi ,T., Younkin, L.H., Saido, T.C., Shoji, M., Ashe, K.H., and Younkin, S.G. 2001. Age-dependent changes in brain, CSF, and plasma amyloid $\beta$ protein in the $\mathrm{Tg} 2576$ transgenic mouse model of Alzheimer's disease. J. Neurosci. 21: 372-381.

King, D.L., Arendash, G.W., Crawford, F., Sterk, T., Menendez, J., and Mullan, M.J. 1999. Progressive and gender-dependent cognitive impairment in the APP(SW) transgenic mouse model for Alzheimer's disease. Behav. Brain Res. 103: 145-162.

Lambert, M.P., Barlow, A.K., Chromy, B.A., Edwards, C., Freed, R., Liosatos, M., Morgan, T.E., Rozovsky, I., Trommer, B., Viola, K.L., et al 1998. Diffusible, nonfibrillar ligands derived from A $\beta 1-42$ are potent central nervous system neurotoxins. Proc. Natl. Acad. Sci. 95: 6448-6453.

Lewis, J., Dickson, D.W., Lin, W.L., Chisholm, L., Corral, A., Jones, G., Yen, S.H., Sahara, N., Skipper, L., Yager, D., et al. 2001. Enhanced neurofibrillary degeneration in transgenic mice expressing mutant tau and APP. Science 293: 1487-1491.
Lim, G.P., Yang, F., Chu, T., Chen, P., Beech, W., Teter, B., Tran, T., Ubeda, O., Ashe, K.H., Frautschy, S.A., et al. 2000. Ibuprofen suppresses plaque pathology and inflammation in a mouse model for Alzheimer's disease. J. Neurosci. 20: 5709-5714.

Locascio, J.J., Growdon, J.H., and Corkin, S. 1995. Cognitive test performance in detecting, staging, and tracking Alzheimer's disease. Arch. Neurol. 52: 1087-1099.

Moechars, D., Lorent, K., Strooper, B.D., Dewachter, I., and Leuven, F.V. 1996. Expression in brain of amyloid precursor protein mutated in the $\alpha$-secretase site causes disturbed behavior, neuronal degeneration and premature death in transgenic mice. EMBO J. 15: 1265-1274.

Moechars, D., Dewachter, I., Lorent, K., Reverse, D., Baekelandt, V., Naidu, A., Tesseur, I., Spittaels, K., Haute, C.V., Checler, F., et al. 1999. Early phenotypic changes in transgenic mice that overexpress different mutants of amyloid precursor protein in brain. J. Biol. Chem. 274: 6483-6492.

Moran, P.M., Higgins, L.S., Cordell, B., and Moser, P.C. 1995. Age-related learning deficits in transgenic mice expressing the 751-amino acid isoform of human beta-amyloid precursor protein. Proc. Natl. Acad. Sci. 92: 5341-5345.

Morgan, D., Diamond, D.M., Gottschall, P.E., Ugen, K.E., Dickey, C., Hardy, J., Duff, K., Jantzen, P., DiCarlo, G., Wilcock, D., et al. 2000. A $\beta$ peptide vaccination prevents memory loss in an animal model of Alzheimer's disease. Nature 408: 982-985.

Morris, J.C. 1993. The Clinical Dementia Rating (CDR): Current version and scoring rules. Neurology 43: 2412-2414.

Mucke, L., Masliah, E., Yu, G.Q., Mallory, M., Rockenstein, E.M., Tatsuno, G., Hu, K., Kholodenko, D., Johnson-Wood, K., and McConlogue, L. 2000. High-level neuronal expression of aß: 1-42 in wild-type human amyloid protein precursor transgenic mice: Synaptotoxicity without plaque formation. J. Neurosci. 20: 4050-4058.

Naslund, J., Haroutunian, V., Mohs, R., Davis, K.L., Davies, P., Greengard, P., and Buxbaum, J.D. 2000. Correlation between elevated levels of amyloid $\beta$-peptide in the brain and cognitive decline. JAMA 283: 1571-1577.

Pompl, P.N., Mullan, M.I., Bjugstad, K., Arendash, G.W. 1999. Adaptation of the circular platform spatial memory task for mice: use in detecting cognitive impairment in the APP(SW) transgenic mouse model for Alzheimer's disease. J. Neurosci. Methods 87: 87-95.

Poorkaj, P., Bird, T.D., Wijsman, E., Nemens, E., Garruto, R.M., Anderson, L., Andreadis, A., Wiederholt, W.C., Raskind, M., and Schellenberg, G.D. 1998. Tau is a candidate gene for chromosome 17 frontotemporal dementia. Ann. Neurol. 43: 815-825.

Quon, D., Wang, Y., Catalano, R., Scardina, J.M., Murakami, K., Cordell, B. 1991. Formation of beta-amyloid protein deposits in brains of transgenic mice. Nature 352: 239-241.

Roher, A.E., Chaney, M.O., Kuo, Y.M., Webster, S.D., Stine, W.B., Haverkamp, L.J., Woods, A.S., Cotter, R.J., Tuohy, J.M., Krafft, G.A., et al. 1996. Morphology and toxicity of A $\beta-(1-42)$ dimer derived from neuritic and vascular amyloid deposits of Alzheimer's disease. J. Biol. Chem. 271: 20631-20635.

Schenk, D., Barbour, R., Dunn, W., Gordon, G., Grajeda, H., Guido, T., Hu, K., Huang, J., Johnson-Wood, K., Khan, K., et al. 1999. Immunization with amyloid- $\beta$ attenuates Alzheimer-disease-like pathology in the PDAPP mouse. Nature 400: 173-177.

Spillantini, M.G., Murrell, J.R., Goedert, M., Farlow, M.R., Klug, A., and Ghetti, B. 1998. Mutation in the tau gene in familial multiple system tauopathy with presenile dementia. Proc. Natl. Acad. Sci. 95: 7737-7741.

Terry, R.D., Masliah, E., Salmon, D.P., Butters, N., DeTeresa, R., Hill, R., Hansen, L.A., and Katzman, R. 1991. Physical basis of cognitive alterations in Alzheimer's disease: Synapse loss is the major correlate of cognitive impairment. Ann. Neurol. 30: 572-580.

Wang, J., Dickson, D.W., Trojanowski, J.Q., and Lee, V.M. 1999. The levels of soluble versus insoluble brain $\mathrm{A} \beta$ distinguish Alzheimer's disease from normal and pathologic aging. Exp. Neurol. 158:328-337.

Westerman, M., Cooper-Blacketer, D., Mariash, A., Kotilinek, L. Kawarabayashi, T., Younkin, L.H., Carlson, G., Younkin, S.G., and Ashe, K.H. The relationship between Aß and memory in the Tg2576 mouse model of Alzheimer's disease. J. Neurosci. (in press). 


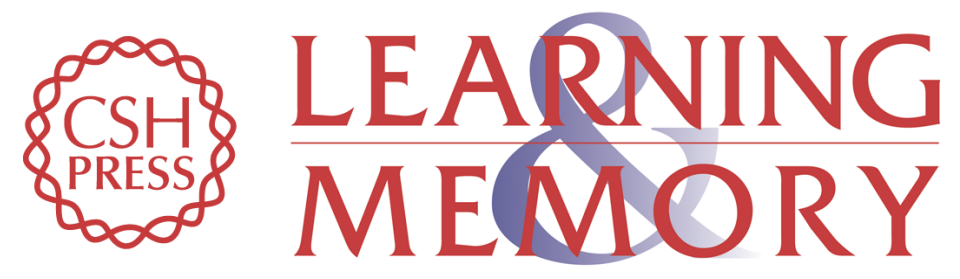

\section{Learning and Memory in Transgenic Mice Modeling Alzheimer's Disease}

Karen Hsiao Ashe

Learn. Mem. 2001, 8:

Access the most recent version at doi:10.1101//m.43701

References This article cites 50 articles, 16 of which can be accessed free at:

http://learnmem.cshlp.org/content/8/6/301.full.html\#ref-list-1

License

Email Alerting Receive free email alerts when new articles cite this article - sign up in the box at the Service top right corner of the article or click here. 